C O L A B O R A Ç Ã O E S P E C I A L

\title{
PIONEIRAS E CONSTRUTORAS: \\ BREVE NOTA SOBRE A CONTRIBUIÇÃO DE ANGELA DE CASTRO GOMES E LUCIA LIPPI OLIVEIRA À TRAJETÓRIA DO CPDOC
}

Pioneers and constructors: a notice about the contribution of Angela de Castro Gomes and Lucia Lippi Oliveira to the course of CPDOC

LUCIANA HEYMANN

http://dx.doi.org/10.1590/S2178-14942016000200012

Luciana Heymann é professora da Escola de Ciências Sociais (CPDOC) da Fundação Getulio Vargas (FGV) e editora de Estudos Históricos (luciana.heymann@fgv.br). 


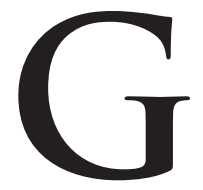

ostaria de começar saudando afetuosamente as professoras Lucia Lippi e Angela de Castro Gomes, homenageadas desta noite. Saúdo, em seguida, o diretor da Escola de Ciências Sociais da FGV/CPDOC, professor Celso Castro; o professor João Marcelo Maia, que preside esta cerimônia, e a comunidade do CPDOC: professores, pesquisadores, analistas de documentação, funcionários, estagiários, alunos. Muito especialmente, saúdo os amigos e colegas, professores e pesquisadores de outras instituições, que vieram prestar sua homenagem às professoras Lucia e Angela, entre os quais alguns queridos colegas que por aqui passaram, em passado longevo ou recente, ex-alunos e orientandos das homenageadas. Boa noite a todos. É um grande prazer recebê-los aqui esta noite.

Coube a mim a honra de destacar a contribuição das professoras Lucia Lippi e Angela de Castro Gomes à trajetória do CPDOC. Uma tarefa fácil, e quase dispensável, haja vista a razão pela qual nos reunimos hoje aqui: celebrar um título que reflete exatamente o reconhecimento por essa contribuição. Dispensável também, poderíamos pensar, porque o público que hoje aqui se reúne - em sua maioria composto por colegas que conviveram com ambas como pesquisadoras e depois professoras do CPDOC -, conhece essa contribuição e, portanto, pode bem aquilatar as razões pelas quais os professores que hoje compõem a Congregação da Escola de Ciências Sociais propuseram, em junho do ano passado, a concessão do título às duas professoras. Em certo sentido, portanto, falar sobre a contribuição de Lucia e Angela para a trajetória institucional do CPDOC é chover no molhado!

Como historiadores e cientistas sociais, sabemos, porém, que a memória é fundamental nos processos de significação do presente. Sabemos que é ela que conecta os grupos sociais à sua história, estabelecendo, com isso, as condições de identificação dos indivíduos a um passado comum. Aprendemos cedo, em nossa própria formação intelectual, que onde não há passado compartilhado não há mais grupo, pois, quando dele não mais nos lembramos, a ele não mais pertencemos. 0 esquecimento e o silêncio são, nesse sentido, mecanismos por meio dos quais se anula o passado, dele fazendo tábula rasa para o futuro.

Onde há memória e ela é narrada, ao contrário, as identidades são ativadas e constroem-se as condições sociais do pertencimento. É por isso; porque estamos aqui para celebrar nossa conexão com uma história da qual nos orgulhamos e na qual nos reconhecemos como 
profissionais e intelectuais, que faz sentido falar - ainda que de forma breve e inevitavelmente lacunar - da contribuição de Lucia e Angela para a trajetória desta instituição. Mais do que isso, para a conformação de um ethos que funciona como elemento agregador para o conjunto de professores, reunindo contemporâneos das homenageadas, aqueles que foram por elas formados, direta ou indiretamente, e também a geração mais jovem de professores que, por muitas e diversas razões, se reconhecem pertencendo à tradição intelectual e institucional que ambas ajudaram a estruturar e a consolidar.

Por todas essas razões, a honra que me coube é também diretamente proporcional à responsabilidade da tarefa, bem como à minha alegria pessoal em dela me ocupar. Essa responsabilidade deve-se, entre outras coisas, ao fato de que não falo apenas por mim, e é importante dizê-lo, mas por todos os colegas de trabalho. Pois se é verdade que a concessão do título partiu de proposta dos professores acolhida na Congregação, também é verdade que ela expressa um reconhecimento que extrapola o grupo de professores para abarcar todos os profissionais que atuam no CPDOC. Assim, espero que minhas palavras encontrem ressonância em cada um de meus colegas presentes; espero que elas traduzam, em alguma medida, um sentimento partilhado, ainda que vivenciado de maneiras distintas e individuais.

De outro lado, porém, é inevitável falar por mim e a partir da minha própria trajetória de mais de 30 anos no CPDOC, primeiro como estagiária, depois como pesquisadora e, mais recentemente, como professora. Minha carreira e minha identidade profissionais foram forjadas nesta casa, onde tive o prazer e o privilégio de conviver e de me profissionalizar no convívio com Lucia e com Angela, mas não apenas com elas. Estão aqui presentes colegas que foram fundamentais na formação da minha geração e de gerações mais jovens. Não é o caso de citar nomes - e seria um risco fazê-lo de improviso -, mas espero que saibam que estão sendo lembrados e se sintam também homenageados. Porque escolas como o CPDOC - e aqui não me refiro à instituição de ensino, mas a um ambiente de formação profissional - são obras de muitos corações e mentes, são projetos coletivos. Entendo que celebramos também essa trajetória institucional, e ela não poderia estar mais bem representada. Lucia e Angela, além de expoentes em suas áreas de produção intelectual, foram artífices fundamentais de um projeto tão inovador quanto potente chamado CPDOC.

Seria impossível reconstituir de maneira fiel as décadas dedicadas por Lucia e Angela a esta instituição e, por isso, destacarei as realizações que me parecem ter contribuído de maneira mais significativa para a construção do projeto coletivo, deixando a análise de suas obras e de seu impacto no campo acadêmico para meus colegas, Bernardo Buarque de Hollanda e Paulo Fontes, que, em suas trajetórias, com originalidade e extrema competência, seguem eles próprios trilhas abertas por essa produção intelectual. É bom lembrar, porém, que nossas falas 
procuram dar conta de dimensões que estiveram sempre profundamente imbricadas, já que muitas obras produzidas por Lucia e Angela são tributárias de reflexões, atividades e pesquisas desenvolvidas no contexto institucional e, nesse sentido, repercutem a vitalidade do CPDOC. Para essa geração pioneira - mas penso que não apenas para ela - 0 ambiente institucional e os projetos coletivos marcaram de maneira indelével as trajetórias intelectuais individuais.

Inicio meu comentário acerca da contribuição de nossas homenageadas registrando que ambas ingressaram no CPDOC, à época ainda ligado ao INDIPO, Instituto de Direito Público e Ciência Política da FGV, no mesmo ano, 1976.' Nessa época, Lucia já era mestre em Ciência Política pelo IUPERJ, onde se titulara três anos antes com uma dissertação sobre o PSD. ${ }^{2}$ Tanto no curso de Sociologia e Política na PUC-Rio como no luperj, Lucia foi colega de turma de Celina Vargas do Amaral Peixoto, que fundou o CPDOC em 1973. Segundo Lucia, em uma entrevista, a aproximação entre elas se deu a partir de um trabalho de curso escrito a seis mãos, com Celina Vargas e Maria Aparecida Hime, no qual se desenharam interesses comuns de pesquisa. ${ }^{3} 0$ trabalho versava sobre o contexto político da Revolução de 1930 e, transformado em artigo, foi publicado na Dados em 1970.

Lucia foi convidada por Celina para ingressar no CPDOC com o objetivo de coordenar um projeto de pesquisa chamado Brasiliana, originalmente desenhado por Aspásia Camargo, que pretendia inventariar a produção intelectual da década de 1930 de maneira a dar respaldo teórico e bibliográfico ao trabalho de pesquisa nos arquivos que começavam a chegar - em um primeiro momento, os arquivos de Getulio Vargas e Oswaldo Aranha. Desse projeto resultou o livro Elite intelectual e debate político nos anos 30, coordenado por Lucia e publicado em 1980. ${ }^{4}$

Angela chegou ao CPDOC no mesmo ano de 1976, como disse, a convite de Aspásia, enquanto ainda cursava o mestrado em Ciência Política no IUPERJ e após concluir sua graduação em História na UFF. [Engraçado pensar que Angela não nasceu doutora! ] 0 convite era para trabalhar na pesquisa que resultou no livro Regionalismo e centralização política: partidos e Constituinte nos anos trinta, organizado por Angela e também publicado em 1980, reunindo textos de vários colegas e um capítulo sobre representação de classe, de sua autoria, que incorporava reflexões de Burguesia e trabalho, fruto de sua dissertação de mestrado, publicado no ano anterior e reeditado em $2014 .^{5}$

Não vou desfiar a vasta produção intelectual das nossas homenageadas - não precisam ficar preocupados! Mas preciso mencionar o livro que ambas organizaram, juntamente com Mônica Velloso, publicado em 1982. Estado Novo: ideologia e poder já anunciava uma perspectiva de análise que, de maneiras distintas, marcaria a produção das duas pesquisadoras. Tratava-se de enfrentar o desafio de traçar o perfil ideológico do Estado Novo, não de maneira unívoca, ou partindo da comparação com as experiências fascistas europeias, mas de 
dar visibilidade às matrizes que conformaram o ideário autoritário e nacionalista do regime, funcionando como vetores da trama de "tradição" e "modernização" articulada no projeto de construção do Estado nacional. ${ }^{6}$

Fica claro, ao revisitar os registros acerca dessa produção intelectual, que os pesquisadores do CPDOC se debruçavam sobre um período da história brasileira que havia sido pouquíssimo estudado até então por historiadores nacionais, e que o faziam em três frentes: organizando fontes primárias (e definindo procedimentos para essa tarefa); produzindo cronologias, verbetes e levantamentos bibliográficos, e desenvolvendo um campo de pesquisa que aliava o estudo da história política das décadas de 1920, 30 e 40 à reflexão acerca do pensamento social que informava os atores sociais do período. Na análise de Elide Rugai publicada no livro comemorativo pelos 30 anos do CPDOC, o trabalho de Lucia e Angela - mas também o de Helena Bomeny - foi fundante dessa tradição, marcada pelo que ela chamou de "tese do tempo", ou seja, a preocupação de articular presente, passado e futuro, analisando não apenas como diversas temporalidades informavam o pensamento político brasileiro dos anos 30, mas como o presente dos anos 70 e 80 se articulava a tradições políticas autoritárias. ${ }^{7}$

Não é possível deixar de mencionar o lugar da interdisciplinaridade nessa tradição de estudos, "pedra angular" na montagem do próprio CPDOC. ${ }^{8}$ Olhada com desconfiança nos primeiros tempos, a articulação entre historiadores, sociólogos, cientistas políticos e antropólogos deu uma feição única à produção acadêmica e ao ethos institucional, marcando profundamente muitas trajetórias e projetos. Penso que Lucia e Angela foram das mais "contaminadas" por esse ambiente plural, haja vista a variedade de picadas de pesquisa que abriram, as estradas de reflexão que pavimentaram e as pontes que lançaram para fora do CPDOC e que nos conectaram de forma definitiva a outros grupos e debates.

0 trabalho de produção de infraestrutura documental e informacional é outra marca original que não se perdeu. Ao contrário, se intensificou no próprio CPDOC, e se multiplicou em centros de documentação e memória criados em todo o país nos anos 1980 e 1990, com apoio ou sob inspiração do nosso Centro.

A sociologia histórica que marcou a geração que criou o CPDOC - Celina Vargas, Aspásia Camargo, mas também Alzira Abreu - parece ter funcionado como matriz responsável tanto pelo apreço à interdisciplinaridade como pelo interesse por uma história política renovada, não factual, mais próxima de uma história social do político e da política. A coordenação de Pesquisa esteve sob a batuta de Aspásia nos primeiros anos, e depois foi assumida por Lucia, ainda nos anos 1980, no que já foi chamado de "primeira mudança de guarda". 9

Antes de a pesquisa se estruturar de maneira mais sólida no CPDOC, porém, mas profundamente inspirada por essa marca de origem, teve início a história oral, metodologia 
integradora de diferentes tradições, entendida então como uma maneira de preencher as lacunas encontradas na documentação, e como forma de integrar à análise a interpretação dos atores. Definir metodologicamente os objetivos da história oral marcou o tipo de estudo das elites feito no CPDOC desde então. Nesse ponto, não posso deixar de me referir à contribuição de Angela a esse campo de investimento, não apenas no período em que coordenou o então setor de História Oral, entre 1988 e 1992, mas como uma pesquisadora que avançou os estudos sobre memória no Brasil.

Além disso, junto com Marieta de Moraes Ferreira e Verena Alberti, Angela foi fundamental na articulação de um debate interinstitucional e na internacionalização do CPDOC, pela via da história oral. Mas não foi apenas isso. Escutar as entrevistas feitas por ela com membros da elite política e jurídica, mas também com imigrantes e sindicalistas, é uma aula de respeito e reflexão dialógica sem perder a astúcia jamais! Muitos de nós bebemos nessa fonte e nela nos inspiramos no desenvolvimento de projetos de história oral ao longo das últimas décadas.

A presença de Lucia à frente do Setor de Pesquisa e, pouco depois, de Angela à frente da História Oral deu novo impulso às conexões do CPDOC com o universo acadêmico, gerando iniciativas como a publicação dos Textos CPDOC, impressos que divulgavam as pesquisas desenvolvidas na casa, mas levando também a uma participação muito ativa em fóruns acadêmicos como a ANPOCS, a ANPUH e, um pouco mais tarde, a Associação Brasileira de História Oral. Nessas entidades, a presença de Lucia e Angela foi marcante e agregadora, organizando grupos ou simpósios temáticos reconhecidos e concorridos. Talvez um dos melhores exemplos dessas conexões extramuros seja o GT de Pensamento Social da ANPOCS, coordenado por Lucia no momento de sua criação, depois por Angela e também por Helena, do qual muitos colegas participaram e no qual continuamos bem representados pelo colega João Marcelo Maia.

Uma das empreitadas institucionais mais ousadas e bem-sucedidas à qual se dedicaram nossas homenageadas, ainda na década de 1980, foi, sem dúvida, a criação da revista Estudos Históricos, cujo primeiro número foi lançado na Casa de Cultura Laura Alvim, na celebração pelos 15 anos do CPDOC. No manifesto de lançamento desse primeiro número, dedicado aos "Caminhos da Historiografia", os editores reafirmam a aposta em uma visão integrada de história e ciências sociais, propondo criar um veículo de divulgação de uma pesquisa multidisciplinar voltada para a história do Brasil.

A primeira equipe editorial a assumir a revista - que desde o início adotou o formato de uma editoria colegiada de três pesquisadores - foi composta por Lucia, Angela e Gerson Moura, falecido precocemente quatro anos depois, e um dos poucos varões a aparecer nos relatos sobre os tempos heroicos do CPDOC. Lucia integrou a equipe editorial por muitos anos após a criação da revista, e Angela dela participou em dois períodos, de 1988 a 1994, e 
depois, de 2007 a 2010. Editada ininterruptamente há 28 anos e gozando do reconhecimento da comunidade acadêmica, Estudos Históricos é uma das joias da Coroa. A equipe editorial se renova a cada quatro anos e vários colegas já tiveram oportunidade de contribuir para esse projeto, tão absorvente quanto desafiador. Hoje tenho a satisfação de dividir a editoria com os colegas Marco Aurélio Vannucchi e Paulo Fontes e acabamos de assumir um desafio novo: a partir de 2016 a revista terá periodicidade quadrimestral, ao invés de semestral, o que aumenta em $50 \%$ a responsabilidade de manter a qualidade que herdamos!

Lucia ainda era editora da revista quando assumiu a direção do CPDOC, entre 1996 e 1999. Era um momento difícil para a Fundação Getulio Vargas, em que os financiamentos públicos haviam escasseado e o autofinanciamento era palavra de ordem de difícil tradução para um centro de pesquisa e documentação. Projetos de livros comemorativos de natureza histórica, de bancos de entrevistas de história oral e centros de memória para empresas ou entidades públicas começaram a ser elaborados já no final dos anos 80, e se multiplicaram nos 90. Foi um período de grandes desafios e dificuldades, mas que, sem dúvida, redundou em muitos aprendizados.

Lucia sempre apostou na inovação, e o primeiro "produto tecnológico" do CPDOC foi tributário dessa aposta pessoal em um contexto que exortava à criatividade. O CD-Rom A Era Vargas, $1^{\circ}$ tempo, lançado em 1997, foi um projeto coordenado por ela. Hoje temos a sensação de falar de um objeto retrô, mas, à época, não havia muitas iniciativas semelhantes na nossa área. Me recordo de um mapa animado que integrava o CD, especialmente interessante, que reproduzia o avanço da Coluna Prestes - e não poderia ser diferente já que à frente do projeto estava uma pesquisadora fascinada pelo espaço e suas fronteiras.

Lucia ainda se dedicaria a esse formato de produto em um projeto de pesquisa acerca do prédio do Ministério da Fazenda, no Rio de Janeiro, no início dos anos 2000. Na ocasião, a arquitetura e o urbanismo entraram com força em sua agenda de pesquisa, articulando projetos para os quais concorreram outros pesquisadores da casa. Capítulos da memória do urbanismo carioca, livro organizado com Américo Freire, publicado em 2002, resultou da aproximação entre os interesses de Lucia pelo espaço urbano e as reflexões do grupo de pesquisa sobre o Rio de Janeiro, do qual Américo é um dos esteios. ${ }^{10}$

Desse projeto resultou ainda o livro Cidade: história e desafios, organizado por Lucia e lançado no mesmo ano, reunindo capítulos de colegas da casa - o próprio Américo, Marly Motta, Dulce Pandolfi e Mario Grynszpan - e de especialistas dos campos do patrimônio e da gestão urbana. ${ }^{11}$ Cito essas publicações menos pelo que representaram na trajetória intelectual de Lucia, que será tratada a seguir, e mais pelo novo campo de estudos aberto no CPDOC, reinventado anos mais tarde pelas mãos de jovens pesquisadoras que ingressaram na casa. 
Na mesma época, Angela também esteve à frente de dois projetos institucionais de grande porte que comportaram desafios bastante diferentes entre si. 0 primeiro, cuja coordenação dividiu com Dulce Pandolfi e Verena Alberti, tinha por objetivo a produção de um livro sobre a história do Brasil republicano voltado para o grande público - foi o primeiro produzido no CPDOC com essas características -, privilegiando não uma narrativa cronológica, mas a abordagem de temas-chave para a compreensão da história do país. A República no Brasil, também publicado em 2002, reuniu textos de outros sete colegas do CPDOC, entre os quais a própria Lucia, em um cuidadoso projeto iconográfico a cargo de Mônica Kornis. ${ }^{12}$

0 segundo projeto, que menciono aqui pelo que significou em termos de um trabalho institucional agregador, para além da qualidade das pesquisas que nele desaguaram, foi o PRONEX Direitos e Cidadania, financiado pelo CNPq e pela Faperj. Sediado no CPDOC, o projeto contou com a participação de muitos pesquisadores da casa, mas também de outras instituições, como UFF, UFRJ e Casa de Rui Barbosa, tendo como resultados diretos dois seminários, um número da Estudos Históricos e dois livros: Direitos e cidadania: justiça, poder e mídia e Direitos e cidadania: memória, política e cultura, ambos lançados em 2007.13

Os projetos sobre o urbanismo, coordenados por Lucia, e esses dois projetos coordenados por Angela são exemplares de uma dinâmica institucional que ambas ajudaram a impulsionar, ao aglutinar pesquisadores de diferentes perfis e gerações, de dentro e de fora do CPDOC, em torno de temas de grande atualidade. Não por acaso, cidade e cidadania não mais sairiam da pauta de pesquisa do CPDOC.

Nos anos 2000, além dos projetos de pesquisa, gestou-se outro projeto institucional para o qual nossas homenageadas foram - e ainda são - fundamentais. Me refiro ao Programa de Pós-graduação em História, Política e Bens Culturais, cujas atividades tiveram início com o Mestrado Profissional em Bens Culturais e Projetos Sociais, em 2003, posteriormente ampliadas com o Mestrado Acadêmico e o Doutorado, em 2007.

0 projeto de um mestrado já havia rondado o CPDOC no início dos anos 80, quando ainda havia financiamento público para isso, mas, à época, os desdobramentos administrativos que decorreriam de uma Pós foram considerados excessivos para a estrutura do Centro. Vinte anos depois, porém, quando a CAPES abriu a possibilidade de canalizar expertises profissionais em mestrados de cunho mais aplicado, a chance não foi desperdiçada.

Sob o impulso de Marieta de Moraes Ferreira, então diretora do CPDOC, Mario Grynszpan costurou um projeto que aliava nossa experiência na produção e gestão de bens culturais à reflexão acerca de projetos sociais que têm a Cultura como elemento articulador. Esse projeto sublinhava que a tradição de pesquisa do CPDOC em história do Brasil, o desenvolvimento de metodologias para a produção e o tratamento de fontes históricas e a marca 
da interdisciplinaridade nos qualificavam a levar adiante um mestrado profissional pioneiro na área de História. A aprovação do projeto deu início à atividade regular de ensino no CPDOC, expandida também para a Graduação, em 2006, já sob a direção de Celso Castro.

No projeto da pós, a presença de Lucia e Angela funcionou, sem dúvida, como caução e como promessa: se um projeto de mestrado profissional despertava ainda alguma desconfiança na área, o corpo docente lhe conferia total credibilidade! 0 primeiro processo seletivo atraiu quase cem candidatos, e mostrou o acerto da aposta. Nossas homenageadas abraçaram o projeto com enorme entusiasmo. Lucia já orientou 22 dissertações de mestrado no Programa, entre profissionais e acadêmicas, e 2 teses de doutorado; Angela orientou 12 dissertações e 7 teses de doutorado.

É importante lembrar que, para a estruturação da pós-graduação, foi fundamental contar com Angela na coordenação do Programa de Pós-graduação entre 2007 e 2010, quando iniciamos as atividades do segmento acadêmico. Sua visão da pós-graduação em História, no Brasil, nos balizou em decisões importantes, traduzidas tanto nos instrumentos de regulação dos cursos como em diretrizes de ordem acadêmica.

Nos últimos anos, tendo assumido essa coordenação depois de Angela e Mônica Kornis, que esteve no cargo de 2010 a 2012, percebo claramente a marca de qualidade impressa pelo grupo que criou a pós-graduação, continuada por docentes desse grupo inicial e também por novos colegas. Essa percepção se apoia na análise das trajetórias dos egressos, mas também em sinais menos palpáveis como o que colhi na primeira aula de uma disciplina obrigatória que estou ministrando no Mestrado Profissional este semestre: em uma turma de 20 novos alunos, pelo menos cinco disseram ter optado pelo curso após conversarem com alunos ou ex-alunos. Alguém poderia perguntar: o que as professoras Lucia e Angela têm a ver com isso? Pois elas têm tudo a ver! Não apenas porque orientaram excelentes trabalhos, mas porque, de variadas formas, nos ensinaram o ofício.

Com esse gancho, chego ao final da minha fala. Além das inovações que empreenderam, da consolidação de um tipo de produção intelectual que passou a caracterizar e a distinguir o CPDOC, do estabelecimento de redes fundamentais para a nossa vitalidade acadêmica, a contribuição de nossas professoras eméritas se fez sentir também nos pequenos gestos, na generosidade de uma conversa ou de uma sugestão bibliográfica, na aproximação entre pessoas, no estímulo para que seguíssemos uma determinada trilha de investigação. Sou pessoalmente tributária dessa troca intelectual e desse aprendizado, os quais agradeço de público, com a certeza de que não falo apenas por mim.

Muito obrigada. 


\section{NotAs}

10 CPDOC se tornou uma unidade autônoma da FGV apenas em 1985.

2 A dissertação, intitulada O Partido Social Democrático, foi orientada pelo Prof. Wanderley Guilherme dos Santos e defendida em 1973.

3 Cf. Fundação Getulio Vargas: concretização de um ideal. Organizadora: Maria Celina D'Araújo. Rio de Janeiro: Ed. FGV, 1999, 334 p. Disponível em: http://cpdoc.fgv.br/producao_intelectual/arq/72.pdf (acesso em 29/05/2016). A entrevista pode ser encontrada da página 259 à 267.

4 OLIVEIRA, Lucia Lippi. Elite intelectual e debate político nos anos 30. Uma bibliografia comentada. Brasília/ Rio de Janeiro: INL/FGV, 1980. 355p.

5 Cf. Regionalismo e centralização política: partidos e Constituinte nos anos 30. Coordenação: Angela de Castro Gomes [et. al]. Rio de Janeiro: Nova Fronteira, 1980, 501p. Disponível em http://cpdoc.fgv.br/producao_intelectual/arq/141.pdf (acesso em 29/05/2016).

6 Cf. OLIVEIRA, Lucia Lippi; VELLOSO, Mônica Pimenta; GOMES, Angela Maria de Castro. Estado Novo: ideologia e poder. Rio de Janeiro: Zahar Ed. 1982, 166p. Disponível em http://cpdoc.fgv.br/producao_intelectual/ arq/132.pdf (acesso em 29/05/2016).

7 Cf. BASTOS, Elide Rugai. O CPDOC e o pensamento social brasileiro. In: CPDOC 30 anos. Textos de Célia Camargo...[et al]. Rio de Janeiro: Ed. FGV/CPDOC, 2003, pp 97-119.

8 A expressão é de Aspásia Camargo: "Essa ideia interdisciplinar do CPDOC foi uma pedra angular importante na montagem da instituição e na produção que ela veio a desenvolver dali para a frente." (Cf. Fundação Getulio Vargas: concretização de um ideal, p. 243).

9 Cf. Fundação Getulio Vargas: concretização de um ideal, p. 249.

10 Cf. Capítulos da memória do urbanismo carioca: depoimentos ao CPDOC. Organizadores: Américo Freire e Lucia Lippi Oliveira. Rio de Janeiro: Folha Seca, 2002, 232 p. il. Disponível em http://cpdoc.fgv.br/producao_intelectual/arq/1251.pdf (acesso em 29/05/2016).

11 Cf. Cidade: história e desafios. Organizadora: Lucia Lippi Oliveira. Rio de Janeiro: Ed. FGV, 2002, 295 p. Disponivel em http://cpdoc.fgv.br/producao_intelectual/arq/1264.pdf (acesso em 29/06/2016).

12 Cf. A República no Brasil. Coordenadoras: Angela de Castro Gomes, Dulce Chaves Pandolfi e Verena Alberti. Rio de Janeiro: Nova Fronteira/CPDOC, 2002, 559 p.

13 Cf. GOMES, Angela Maria de Castro. Direitos e cidadania: justiça, poder e mídia. Rio de Janeiro: FGV, 2007, 329 p.; . Direitos e cidadania: memória, política e cultura. Rio de Janeiro: FGV, 2007, 320 p. 